\title{
Hidden Children: Refugee Fostering in Guinea
}

\author{
International Rescue Committee, \\ Host Country Foster Care Project in Guinea
}

\author{
Catherine Moller and Courtney Sara Minard
}

\begin{abstract}
One of the most vulnerable yet overlooked groups within situations of forced migration is that of refugee children who have been separated from their families as a result of armed conflict and subsequently absorbed by foster families in the countries to which they have fled. Based on extensive fieldbased research, this paper presents protection problems and poses solutions for such refugee children in Guinea, West Africa, including their access to rights such as family tracing; cultural and linguistic continuity; and education, health, and well-being. The paper also considers long-term integration options for refugee children living in Guinean foster families. The paper concludes by analyzing the use of a human rights framework to alleviate human suffering in this particular situation of forced migration.
\end{abstract}

\section{Résumé}

L'un des groupes les plus vulnérables, quoique des plus négligés, parmi tous ceux qui se trouvent poussés à la migration forcée, est celui d'enfants réfugiés séparés de leurs familles par des conflits armés et qui ont éventuellement été absorbés par des familles d'accueil dans les pays où ils ont fui. Se fondant sur des recherches approfondies conduites sur le terrain, cet article aborde les problèmes de protection et propose des solutions pour des enfants pareils se trouvant en Guinée, Afrique de l'Ouest, y compris leur accès à certains droits, comme par exemple pour retracer leurs familles, la continuité culturelle et linguistique, ainsi que l'éducation, les soins de santé et le bien-être. L'article considère aussi les options possibles menant à des solutions dur- ables pour des enfants réfugiés vivant dans des familles d'accueil guinéennes. L'article conclut avec une analyse de l'utilisation d'une approche des droits de la personne pour soulager les souffrances humaines dans la situation en espèce de migration forcée.

\section{Introduction}

During the rebel attack in Freetown [Sierra Leone], my mother was running with me and the rebels shot her in her head and she died. I didn't know where my father and brother were. Then, I saw people running and I followed them and we came to Guinea. When we came to Forecariah, I was suffering, begging people for food. When I saw this mother [current foster mother], I . . explained to her that I had nobody there to take care of me and I asked her to take me along and she accepted.

- Mohamed Kamara, age 9, refugee from Sierra Leone $^{1}$

$\mathrm{O}$ ne of the most vulnerable yet overlooked groups within situations of forced migration is that of refugee children who have been separated from their families as a result of armed conflict. ${ }^{2}$ This is especially true for those children who are subsequently absorbed by foster families in the countries to which they have fled. Their human rights and the standards for their care are detailed in the Convention on the Rights of the Child, the African Charter on the Rights and Welfare of the Child, as well as Refugee Children: Guidelines on Protection and Care, which is published by the United Na- 
tions High Commission for Refugees (UNHCR). ${ }^{3}$ But how do these established rights and standards actually improve the lives of these children?

The civil wars in Sierra Leone and Liberia have led to the exodus of more than five hundred thousand refugees to Guinea since 1989. As indicated by the story of Mohamed Kamara, armed attacks separate refugee children from their parents, leaving them vulnerable and alone in Guinea. Refugee families in and around refugee camps eventually take most of these "separated" children into informal foster care arrangements. Other separated refugee children are cared for by Guinean families or survive on their own in the streets of Guinean towns and villages. Some of these children are well taken care of by their foster parents, but others have been trafficked for domestic or manual labour, sexually exploited, or forcibly recruited into militia groups. ${ }^{4} \mathrm{Few}$ of these separated refugee children are actually orphans, and many have parents or family members who are looking for them. It is estimated that there are from ten thousand to twenty-five thousand separated refugee children in Guinea today. ${ }^{5}$

Around the world, separated refugee children who are absorbed into host-country foster families-such as Sierra Leonean children in Guinean families-face a distinctive set of short- and long-term protection problems. These problems have hitherto lacked adequate attention by the international community because such children are usually undocumented, not in refugee camps, and randomly dispersed throughout large areas. They are "hidden" in a sense and cannot benefit from the services of international organizations and governments.

Access to separated refugee children in host country foster families is also problematized by the personal and political sensitivities surrounding these fostering arrangements: sometimes host country foster families are reluctant to declare the presence of refugee children in their care, and governments may be hesitant to allow aid organizations to assist refugees who are outside of officially designated areas. As in other situations concerning separated refugee children in host country foster homes, little is known about how many Sierra Leonean refugee children are in Guinean foster families, how these children came to be there, and the extent to which they endure human rights violations.

In early 2001, the International Rescue Committee launched a research project to better protect separated refugee children in host-country foster families, taking Guinea, West Africa, as a case study. IRC, an international humanitarian relief organization, provides family tracing and other services to separated refugee children around the world, and has worked in Guinea since 1991. This paper presents the preliminary findings of IRC's ongoing research, which is a part of a larger consortium of research projects made possible by the Social Science Research Council's Forced Migration and
Human Rights Project with funds provided by the Andrew W. Mellon Foundation. The Forced Migration and Human Rights Project will be publishing the final results of its research projects later this year.

This paper details protection problems faced by separated refugee children from Sierra Leone who are living with foster families in Guinea; compares data collected from Guinean foster families with Sierra Leonean refugee foster families; and suggests interventions aimed at improving the protection environment for these children. The paper concludes with an analysis of using a human rights framework to alleviate human suffering in this particular situation of forced migration.

Data collected includes focus group discussions with Guinean and refugee communities and interviews with United Nations officials, Guinean government representatives, Guinean non-governmental organizations (NGOs), and international humanitarian assistance workers. One hundred fifty-eight in-depth household interviews were conducted with 34 Guinean foster parents, 24 Sierra Leonean refugee foster parents, and 101 Sierra Leonean refugee children whose average age was eleven. Only homes in which both natural children and foster children resided were included in the study in order to allow for comparison in treatment. All of the foster households were poor, the average size was eleven people, and nearly all supported themselves with informal-sector work activities. The length of time a foster child had been in a foster home ranged from a few months to over a decade, and the average amount of time was about three and a half years.

The research was limited to families living in Conakry, the capital city, due to recent political and military instability in Guinea. Starting in September 2001, a series of regionally based rebel attacks destabilized the country, killed hundreds, and displaced countless civilians and refugees, many of whom fled to Conakry. Due to this violence as well as widespread anti-refugee sentiment, thousands of refugees were rounded up and harassed, and over thirty-five thousand refugees spontaneously returned to Sierra Leone where their safety was not assured. ${ }^{6}$ Between 10 and 15 per cent of the refugee children we interviewed in Conakry had been separated from their previous caregivers and found themselves in foster care situations with new families as a result of this recent instability. ${ }^{7}$ It should be noted that information gathered in an urban environment differs from that which could be collected in the countryside or in a refugee camp, where the majority of separated refugee children actually live. Data collection in such non-urban environments will be a focus of the continuing research in the future. 


\section{Protection Problems and Interventions}

We found in our research that nearly all foster parents in both Guinean and Sierra Leonean foster families spoke fondly of their foster children and said they were willing to care for them for years to come. Yet when human rights standards for separated refugee children are applied, it is clear that these children face a host of human rights problems. In the discussion below, data from focus group discussions and household interviews illustrates the children's access to various rights such as family tracing and documentation; cultural and linguistic continuity; and standards for interim care like education, health, and well-being. Suggested interventions-also based on human rights standards - are presented as well. The question of longterm integration for separated refugee children fostered in Guinean homes is taken up in Part 3.

\section{Family Tracing and Documentation}

As per the Convention on the Rights of the Child (CRC), to which Guinea is a signatory, every child has the right to know and be cared for by his or her parents, and governments must assist in tracing and reunification efforts (articles 7, 10, 20 and 22). Similar rights are enumerated in articles 13 and 15 of the African Charter on the Rights and Welfare of the Child, to which Guinea is also a signatory. When asked, most of the refugee children in our household survey indicated that they would like some sort of family tracing services.

However, identifying and documenting these children so that they can be provided with such services is a challenging task. It is expensive and time-consuming, and current assistance commitments from donor governments are insufficient to support the needed response. Moreover, foster families are sometimes reluctant to declare the presence of their charges-they may fear that they will be punished or shamed for taking in a refugee child or blamed for not looking for the natural parents. They may desire to keep the child for reasons that range from love to labour exploitation. In our household interviews most of the foster families expressed the view that they consider the refugee children to be "theirs" and that they wanted to keep them, although most also thought that it was a good idea to search for the children's families.

Identification is also made difficult by the lack of awareness of the problems faced by separated refugee children in foster homes. Many foster families believe that in the African cultural context of the extended family, there is simply no such thing as foster child who is not cared for appropriately. There are long-standing West African traditions of taking in orphaned or less fortunate children by extended family members or other families for purposes of training and/or basic care, and such children are often not provided the same benefits as the biological children. Separated refugee children are likely absorbed into foster families along the lines of these long-standing practices.
Access to separated refugee children becomes even more problematic when they are cared for by Guinean foster families. Some Guineans believe refugee children are categorically better off if they are sheltered in a Guinean home, even if they are not able to go to school or are treated in an inferior manner to the natural children. The recent insecurity and anti-refugee sentiment in the country may be prompting some Guineans to conceal their refugee children out of a concern for their security: in our household surveys, about a quarter of the Guinean foster parents remarked that their neighbours are wary or suspicious of the refugee children because their origins are unknown or because they might be "rebels." In contrast, the majority of the Sierra Leonean foster families stated that their neighbors had positive and sympathetic reactions to their foster children and only about 10 per cent reported any negative reaction. Access to refugee children in Guinean homes is also complicated by issues of legitimacy: whereas organizations like UNHCR and IRC have clear mandates for refugee matters and refugee foster families are acclimated to their authority, Guinean families and local officials are not accustomed to such representatives visiting Guinean households and can be less responsive to them.

Although international law on documenting refugee children and providing them with tracing services is clear, overcoming the impediments discussed above is less straightforward. In the course of the research, IRC found that community-based sensitization workshops were helpful to raise awareness about the rights of the child, including family tracing. During and after the workshops, local people and officials became more sympathetic to the cause of separated refugee children and helped to identify them. Human rights are used in the course of such sensitizations to good effect, particularly among officials. However, IRC research staff found that drawing upon personal experience and African and religious traditions is a more compelling method of persuasion for the average Guinean and Sierra Leonean than appeals to international law.

Other potential interventions to assist tracing and documentation efforts include public education campaigns conducted via posters, radio, television, newspapers, and mosques. Legal and policy measures, such as a new law or declaration by the Guinean government, could officially acknowledge the existence of separated refugee children in Guinean foster homes and the rights of these children under the CRC. Such a law or policy might also compel Guinean families to declare the presence of refugee children and allow designated officials into Guinean homes. 
Cultural and Linguistic Continuity

UNHCR's guidelines for refugee children recommend that separated refugee children should be fostered in a family of the child's own community, with "persons from the same areas of origin and intended areas of return, in anticipation of voluntary repatriation, and to ensure linguistic and cultural continuity" (127). This is based on article 20.3 of the CRC and article 15 (2.b.1) of the African Charter, which state that when considering interim care for a separated refugee child, "due regard shall be paid to the desirability of continuity in a child's upbringing and to the child's ethnic, religious, cultural and linguistic background." However, the guidelines do not recommend removal of a refugee child from a mixed ethnic foster care situation for that reason alone (126-27).

Focus group discussions with Guinean and refugee communities and household data collected suggest that problems of religion, language, and adaptation, as well as loss of identity and culture, occur with separated refugee children in foster households. Only about 30 per cent of all foster families shared the same ethnic background of the refugee children in their care. Moreover, over half of the children responded that they did not know anyone of their ethnic group in their neighbourhood. More than a third of the children stated that their mother tongue was one of the languages that they spoke best, but some do not know people with whom they can speak it. Fourteen per cent of the foster children reported that their religion or their biological parents' religion was different than that of their foster families.

Almost half of the foster children surveyed had been given new names by their foster parents, which can obscure the child's ethnic identity and hinder tracing efforts, and is in violation of a child's right to the preservation of identity (CRC Article 8.1). However, the caregivers usually stated that they had to provide new names for the refugee foster children because they did not know the children's given names or that they wanted to help the children to integrate into the family and the community. In a few cases, foster parents said that they gave the children new names in order to conceal the children's identity or to "make the children their own."

Some data suggests that refugee children in Sierra Leonean foster families have better opportunities for cultural and linguistic continuity than in Guinean foster families. In Guinean foster families, only a quarter of the foster parents had the same ethnic identity as their foster children, compared to over 40 per cent in Sierra Leonean foster families. About 40 per cent of children in Guinean foster families have someone in their neighbourhood that speaks their mother tongue, in comparison to two-thirds of foster children in Sierra Leonean families. However, about 40 per cent of the children had been given new names by their Guinean foster parents as opposed to nearly 60 per cent in Sierra Leonean foster families.
International child rights law and standards provide little guidance other than paying "due regard" to cultural and linguistic continuity. However, ethnic and linguistic ties can be maintained or rekindled for separated refugee children in foster homes through special events-such as sport or play-and education programs can help them to learn more about or stay in touch with their background. Public education campaigns and sensitization programs can help foster parents be aware of the negative consequences of changing a refugee child's name and religion.

\section{Interim Care}

As stated in the CRC and the African Charter: "Each child temporarily or permanently deprived of his or her family environment is entitled to special protection and assistance" (article 20.1 and article 23.1, respectively). The two instruments additionally prohibit discrimination, abuse, neglect, or exploitation, and state that each child has the right to the highest attainable standard of health, an adequate standard of living, care necessary for well-being, and education. UNHCR's guidelines on refugee children include the provision of love and nurturance as a standard of care for separated refugee children in foster families, monitoring to ensure that the children's needs are met, and intervention in cases of abuse or neglect; the possibility of family reunification must remain open (126-27).

A large majority of the parents in our study described their foster children in affectionate and approving terms and/or described their natural children closest in age in a similar manner. When refugee children were asked to characterize how they feel about staying with their foster family, nearly all used terms like "safe," "happy," or "relieved." For the most part, those conducting the household interviews observed what they considered to be normal family behaviour of the foster children towards their foster family and vice versa, and neighbors who were interviewed often reconfirmed the good care that refugee children were receiving. Almost all foster parents surveyed indicated that they expect the child to be a part of their family fifteen years from now.

Some foster families struggle to overcome severe poverty in order to provide for their foster children and love them like their natural children. In such families, there may be no effective difference between the foster children and their natural-born foster siblings- - their treatment is predicated only by the economic position of the family which, for example, may be too poor to send either the foster child or the natural children to school.

However, our household data also suggested that other refugee children face discriminatory treatment in 
regard to education, health, food, basic care, and punishment. Approximately two-thirds of the separated refugee children of school-going age (age six or above) whom we surveyed were not attending school. More than half of these children had foster brothers and sisters, the natural children of the family, who attended school regularly. In about 15 per cent of the households, foster children were reportedly not learning any income earning skills_-such as a trade or engaging in apprenticeship - while the natural children of the family were learning such skills. In about 20 per cent of the households, there were refugee children who were in bad health who had not had access to a medical facility, yet the natural children of that family had accessed such services.

In about one third of the households surveyed, the children reportedly either did not eat with their foster family and/or were not allocated equal amounts of food as their foster siblings. Likewise, the refugee children in about a fifth of the households stated that they did not have a covering for themselves when they slept, while the natural children of the household did. In almost 40 per cent of the cases, those conducting the household interviews judged that the foster children were noticeably worse off than their foster siblings in terms of their appearance of health, body cleanliness, or quality of clothing. In nearly 20 per cent of the households, it seemed the foster parent or child perceived that the foster children misbehaved more frequently than the natural children, and in a little over 10 per cent of the households, it seemed that the foster children were punished more harshly. There was also evidence of discrimination in the allocation of household tasks or incomeearning work in about a third of the households visited. In these cases, the foster children did the most work - from tasks like cleaning the toilet to minding the family shop - relative to the natural children. ${ }^{8}$

Evidence of discrimination was evident in approximately equal amounts among Sierra Leonean and Guinean households, but some data suggests that foster children might encounter poorer treatment in Sierra Leonean households. According to the researchers' observations, foster children in Sierra Leonean households seemed worse off than natural children in terms of health, body cleanliness, and clothing by as much as 15 per cent. Sierra Leonean foster families were more than three times more likely to report that their foster children misbehaved more than their natural children. A third of the refugee children in Sierra Leonean foster families reported that they did not have anything with which to cover themselves when they slept at night while the natural children did, as opposed to just 8 per cent of the children in Guinean homes. These results are unexpected given the assumed dynamics of host country and refugee communities-one is tempted to think that refugee children would be better cared for by fellow refugee families-but greater levels of poverty and social discrimination faced by Sierra Leoneans as compared to Guinean foster families may be causal factors. These and other potentially explanatory variables will be explored in future research.

We identified two key issues in the course of our research to help improve interim care for foster children: increasing household resources and community-based approaches.

Guinean and refugee communities in focus-group discussions identified economic status as a primary source of protection problems, and the interim care of foster children, as well as their own children, could arguably be improved if the foster family had more resources to devote to them. But an assistance strategy that simply transferred additional resources to foster parents would not help foster children in all situations. These additional resources might be allocated toward family needs that in no way benefit the refugee child due to discrimination and could also lead to corruption, false cases, community resentment, and the establishment of a precedent for future financial support that would likely not be sustainable. Nonetheless, if appropriate oversight, public relations, and implementation could be maintained, a referral system of services could be offered to qualifying foster families, such as education scholarships and income generation programs. Another approach would be to avoid targeting refugee children directly, but rather to aim assistance at the poorest families within a given community that is known to have a high concentration of separated refugee children. By using objective poverty indicators as the criteria for assistance and not the presence of a refugee foster child, a large portion of the desired population group could be served with a lower incidence of perverse consequences such as false cases and community resentment.

As discussed above, foster parents, especially Guineans, can be reluctant to allow designated officials into their homes to monitor refugee foster care. One practice usefully employed in other parts of the world is to encourage the foster family to sign a "temporary care agreement," which outlines the responsibilities of the foster parents toward their foster children and includes promises to allow designated officials to have access to the children, return them to designated officials if required, and/ or to give them up should children wish reunification with family members. But such temporary care agreements must be introduced carefully. Local communities may feel that international standards are being unfairly imposed on them without adequate consideration of their culture and the help they have extended to refugee children, and this could even 
contribute to anti-refugee sentiment among Guinean communities. Our research showed that legitimacy for international standards can be effectively built by drawing upon local norms - there are a host of West African religious and social practices that support international human rights principles such as providing teaching, love, and nurturance to all children and prohibiting abuse and exploitation. Although gaps between local and international norms need to be negotiated, group discussion and consensus building among foster families can develop locally appropriate rules for treatment of their charges, and sensitization to child rights can help these local solutions to best approximate international standards.

\section{Long-Term Integration}

Providing refugees access to a "durable solution" is essential for the fulfillment of refugees' human rights. According to UNHCR's guidelines on refugee children, long-term solutions for separated refugee children should be based on an individual child's best interests and family reunification should be the first priority (130). With international assistance and when security conditions allow, separated refugee children in Guinea whose families are successfully traced in Sierra Leone are currently voluntarily repatriating to Sierra Leone, and many other separated refugee children in refugee foster families are spontaneously repatriating with their foster families as well.

But what about those separated refugee children in Guinean families who do not want to be reunified or whose families cannot be traced? It might not be in their best interests to return to Sierra Leone when that is not their wish; their links to the country such as language, culture, and family have been severed; and they are well cared for and attached to their foster families and more recent surroundings. Local integration may be the best durable solution option for some separated refugee children in Guinean foster homes, but they may confront a number of problems such as a lack of legal status and discrimination in marriage and inheritance. Adoption, formal guardianship, and best-interest committees are some of the possible interventions discussed below which can help address their long-term integration needs.

\section{Nationality and Legal Status}

Under article 8 of the CRC and article 24.3 of the International Covenant on Civil and Political Rights, it is a human right to have a nationality. UNHCR guidelines on refugee children specify that all refugee children should have the same access to services as national children in order to realize the durable solution of local integration, and an "effective nationality"-at the least a permanent and clear legal status that brings with it an array of human rights—is fundamental to that goal $(106,144)$.

Refugee children living in Guinean foster homes lack such a clear legal standing. They do not have prima facie refugee status because they are not living in designated refugee camps, and there is no specific reference to refugee children in the Guinean Civil Code. However, there are some relevant legal provisions which can be applied towards their protection: the Civil Code does permit naturalization and dual citizenship, as well as a degree of civil rights for foreigners. Article 79 of Guinea's Loi Fondamentale specifies that international treaties approved by the government have a superior authority to national laws, and thus refugees are protected by every international human rights agreement signed by the Guinean government. ${ }^{10}$ Under the Economic Community of West Africa States (ECOWAS) Agreement, citizens of member states such as Sierra Leone who are living throughout Guinea have a host of economic, social, cultural, and civil rights, and they may obtain an ECOWAS residence card/ permit.

Despite the explicit nature of these laws, they currently do not seem to have much practical meaning for refugees nor do most adequately ensure rights and access to state services on the level of Guinean nationals. Guinea's judicial system is still developing, and international laws in particular have limited impact and acceptance. Moreover, it is not known how difficult it would be in practice for refugee children to access such legal provisions or what real benefits accompany the provisions. Legal assistance will be required for those separated refugee children in whose best interests it is to access the Guinean naturalization process or their rights under the ECOWAS Agreement. These children will also require information and counselling to understand these possible options.

The Guinean government may consider creating some sort of special legal status and/or simplified procedures to access citizenship for separated refugee children living in Guinean foster homes. This would be a welcome move that would safeguard a host of children's rights under the CRC in a timely and cost-effective manner. UNHCR's guidelines on refugee children state, "Keeping children in limbo regarding their status hence their security and their future, can be harmful to them" (100).

\section{Social Discrimination}

Non-discrimination of rights is one of the fundamental tenets of the children rights regime and is spelled out in article 2 of the CRC and article 3 of the African Charter.

Even if separated refugee children can attain all of their legal rights, they may still face social discrimination. According to some consulted during this research and focus group discussions, separated refugee children in Guinean foster homes will face protection problems 
as they grow up as a result of negative social attitudes. They argue that a child whose origin is not known or is foreign is a less desirable marriage partner due to cultural and religious norms, although this has less impact on women who assume the identity of the family into which they marry and can also be somewhat mitigated if the marriage partner has an education or job bringing high status or income. In our household survey, 40 per cent of the foster parents in both Guinean and refugee foster homes responded that they thought their foster children might have more difficulties in marrying than their natural children due to the fact that they are refugees from Sierra Leone.

It was also argued by some consulted for this research that in the Guinean Muslim context, and in a society where polygamy is widely practiced, typically only natural children can inherit the belongings, name, and status of the family. Less than half of the foster parents surveyed had given their foster children the surname of the foster father. But surprisingly, the majority of the respondents stated that their foster children would inherit some of their belongings, and most of the other responses were "maybe."11

Although such cultural notions are strongly held, sensitization programs can help to raise awareness concerning discrimination faced by separated refugee children in Guinean society as well as their legal rights. A community-based strategy and sensitization programs, such as the ones described above, would again be appropriate. Protection problems stemming from social discrimination in marriage and inheritance could also be somewhat mitigated by interventions which helped these grown children to become more economically viable, such as skills training and micro-credit programs. This is in keeping with the UNHCR guidelines for refugee children which recommend "assistance towards self-sufficiency," including vocational training and job assistance, in order to help further local integration as a durable solution (144).

\section{Adoption and Guardianship}

According to UNHCR guidelines on refugee children, if family tracing is not successful after at least two years of continuous and concentrated efforts, and if there is no reasonable hope for successful tracing in the future, only then can separated refugee children be considered for other long-term solutions such as legal adoption and guardianship (130).

However, Guinean laws on adoption are restrictive. Although Guinea's civil code specifies that an adopted child can be a foreign national and may take the name of the adopted family as well as inherit from them, the law states that a couple that wishes to adopt together must be married for at least ten years without having produced a child together. Legal adoption also runs counter to local cultural norms and is rare to the point of being virtually unknown in Guinea. Legal adop- tion of a child from another country seems to be an even stranger concept.

Formal guardianship specified in Guinea's civil code includes a council of advisers to look after the interests of a child when a child remains without a father, mother, or guardian chosen by his father. Like legal adoption, these laws are also rarely applied, but, unlike adoption, they are not restrictive and are often followed because they reflect customary practices of the Guinean people. However, it was felt by some consulted for this research that Guineans would not necessarily find such customs applicable to separated refugee children because the children are foreigners.

Our research showed that some foster parents treated their foster children in ways consistent with legal adoption, such as by providing non-discriminatory interim care, passing along their family name, and making provisions for inheritance. Although legal adoption is restrictive, it might be worthwhile to test some cases in order to explore other legal interpretations and draw upon the liberal aspects of the law, observing relevant international standards for adoption in the process. ${ }^{12}$ If successful, legal precedents could be established which would pave the way for other qualifying refugee children to be adopted.

Formal fostering and guardianship systems are integral to the protection of separated refugee children in Guinean families and need to be developed. Although some Guineans may not find traditional practices immediately applicable, fostering systems based on such practices bear exploration because they are usually implemented with the greatest ease and legitimacy. Such interventions should meet UNHCR's standards of care, discussed above, and each child should receive appropriate legal status evidencing their identity and nationality. Formal fostering and guardianship systems should include a comprehensive orientation for caregivers as well as foster care/ guardian agreements that are recognized by local authorities.

\section{Best-Interest Committees}

In human rights law, the "best interests" of the child are always a primary consideration and should guide all interventions for separated refugee children. But how can the long-term best interests of separated refugee children in Guinean foster care be determined? Based upon standards set by the CRC, decisions on durable solutions for separated refugee children must be taken by competent bodies that include experienced child welfare personnel, a legal guardian for the child, and the child's opinion; and 
cases must be thoroughly assessed on an individual basis. ${ }^{13}$

In Guinea, such best-interest committees could be organized by the existing National Committee on Child Protection and could include authorities from government, NGOs, the $\mathrm{UN}$, and refugee communities, as well as case workers, the child's guardian, and/or the child himself or herself. Durable solutions options considered by the committees could include: adoption, formal guardian or fostering arrangements, voluntary repatriation, the acquisition of Guinean citizenship, ECOWAS registration, and measures such as providing micro-enterprise programs as a means to future economic independence. The committees would develop and/or be equipped with criteria for when these options should be applied and procedures for bringing them about so that the child's best interests remain of primary importance.

However, what constitutes the "best interest" of an individual child is not always immediately clear and involves complex questions. In addition to the child's expressed wishes weighted by age and maturity, best-interest determinations must take into account the child's physical safety, options for local integration, immediate and long-term needs, and social and emotional considerations. The length of time, and from what age, spent with a foster family and degree of attachment also need to be considered. Criteria for applying durable solutions options should be based on the child's rights under the CRC, such as family reunification, cultural continuity, nationality, survival and development, access to health services and education, protection from abuse and neglect, and an adequate standard of living. At times, such rights can conflict and so all considerations must be carefully weighed on a case-by-case basis.

\section{Conclusion}

Using human rights standards such as the Convention on the Rights of the Child and the African Charter on the Rights and Welfare of the Child to analyze the situation of separated refugee children in foster families in Guinea has provided an understanding of their broad range of short- and long-term needs, ranging from a lack of access to family tracing, to limits on cultural continuity, to discrimination of treatment by their foster families, and to a lack of a permanent legal status.

Strategically, we found in our research that human rights language provides a common vocabulary for articulating the problems of separated refugee children and sets the agenda for response, allowing us to focus more quickly on the nuts and bolts with local partners rather than discussing general best practices. It was clear, for example, that family tracing services need to be extended to separated refugee children in foster families and that foster situations need to be monitored. We were thus allowed to use our time to consider ways to overcome obstacles in the practical implementation of such overarching goals.
As has often been pointed out, human rights also helps strengthen the justification for humanitarian assistance programs-and resources for those programs-turning "beneficiaries" of assistance into rights-holders with internationally recognized legal rights. Action on their behalf becomes a matter of law, not simply because they have needs that "should" be met. Additionally, this created space for the exploration of responses that could address human rights standards on, for example, cultural and linguistic continuity, longterm solutions such as adoption, and the right to a nationality, that may have otherwise been trumped by the immediate and more widely acknowledged interim assistance needs of children like food, health, and education.

A human rights framework was helpful in our research to raise awareness of standards and influence behavior, but this also had practical shortcomings. For instance, human rights concepts were used among Guinean and refugee communities in community meetings to identify separated refugee children, and our research indicated that similar limited appeals to human rights could be useful in public education campaigns and in signed foster care agreements. However, as noted, we found that references to African traditions and personal experience proved to be more effective than appeals to human rights, as the latter pose the potential to provoke adverse local reactions if communities feel that their specific cultural norms are not being adequately acknowledged. Community-based strategies are needed to ensure international standards are placed in an appropriate local context.

Human rights also had only partial utility in the implementation phase of our research due to the fact that they are general in nature. While they are critical in setting standards for intervention, this is only the first step. Practically speaking, for instance, what is the meaning of paying "due regard" to a child's ethnic, religious, cultural, and linguistic background? How can deeply held cultural notions be changed so that refugee children will not face social discrimination in marriage and inheritance?

And lastly, it is often time consuming and expensive to realize human rights standards such as family tracing, monitoring of foster care, and effective nationality. The international community does not offer enough resources to meet all of these needs, and the human rights framework provides little guidance on how to prioritize among competing protection problems when faced with the reality of scarce resources. For instance, would the numerous human rights standards that must be weighed in the case-by-case determination of best interests ham- 
string best-interest committees? Should the option of adoption be ruled out because it may be too difficult and may prove necessary to introduce a lengthy process of developing new national legislation?

Our research has sought to provide unprecedented documentation of the short- and long-term protection situation of separated refugee children in foster families in Guinea and propose practical solutions. IRC seeks to continue this work in the future by undertaking similar investigations in a rural setting in Guinea and testing potential interventions which can help address the long-term integration needs of refugee children in Guinean households.

\section{Notes}

1. A pseudonym has been used to protect confidentiality.

2. For more information on children affected by armed conflict, please see <http://www.reliefweb.int/ocha_ol/civilians/resources/resou rces11.html $>$ and <http://www.un.org/specialrep/children-armed-conflict/>.

3. United Nations High Commission for Refugees, Refugee Children: Guidelines on Protection and Care.

4. Human Rights Watch, "Forgotten Children of War, Sierra Leonean Refugee Children in Guinea," 1999.

5. Precise demographic information on refugees in Guinea is not available. However, according to UNHCR, the number of refugee children accidentally separated from their families during flight generally represents $2-5$ per cent of the displaced population in any emergency.

6. Human Rights Watch, "Refugees Still at Risk: Continuing Refugee Protection Concerns in Guinea," 2001.

7. Guinean children have also been displaced due to the security problems, and some are living with foster families. Like refugees, these children require special attention and protection assistance.

8. Work allocation was deemed discriminatory when it seemed out of sync with the age and gender division of labour typically found in households of similar socio-economic situations.

9. Durable solution options for refugees typically include voluntary repatriation, access to "third country" asylum, or local integration. Voluntary repatriation is the option most refugees ultimately pursue, and third country resettlement and local integration are often options available only to a comparative few.

10. International human rights instruments ratified by Guinea include the Convention on the Rights of the Child, African Charter on the Rights and Welfare of the Child, Convention Relating to the Status of Refugees and its 1967 Protocol, International Covenant on Civil and Political Rights, International Covenant on Economic and Social Rights, Forced Labour. Convention, OAU Convention Governing the Specific Aspects of Refugee Problems in Africa, and the African (Banjul) Charter on Human and Peoples' Rights.

11. It should be noted, however, that even if foster parents want their refugee foster children to inherit, the inheritance might not necessarily occur. Because customary and religious law is commonly interpreted to prohibit inheritance by non-natural children, rela- tives could be successful in. overturning the stated preferences of the deceased and may receive support in their efforts from local and traditional authorities.

12. United Nations General Assembly 41/85: Declaration on Social and Legal Principles relating to the Protection and Welfare of Children, with special reference to Foster Placement and Adoption Nationally and Internationally (1986); The Hague Convention on Protection of Children and Co-operation in Respect of Inter-country Adoption. (May 1993). 41/85: Declaration on Social and Legal Principles.

13. Refugee Children: Guidelines on Protection and Care, 126, $137,146-47$.

Catherine Moller is manager at the International Rescue Committee's Protection Department, based in New York City. Her background includes various posts in human rights, development, and relief work as well as an MPA from the Woodrow Wilson School, Princeton University, and a BA in cultural anthropology from Barnard College.

Courtney Sara Minard is an MIA candidate at Columbia University, New York City.

The authors wish to acknowledge Ousman Kabia, primary field researcher, who is senior program officer with IRC's Separated Children's Program in Guinea, West Africa; and research advisors Marie de la Soudière, director for IRC's Children Affected by Armed Conflict Unit, New York City; Margaret Green-Rauenhorst, protection department director at the IRC, New York City; and Jacqueline Botte, formerly coordinator with IRC's Separated Children's Program in Guinea, West Africa.

IRC would like to thank everyone who generously contributed time and expertise to this research. We would particularly like to thank the children and their foster parents, Ministry for Social Welfare of the Government of Guinea, United Nations High Commission for Refugees (UNHCR) Guinea, United Nations Children's Fund (UNICEF) Guinea, and Organisation Guinéenne de Défense des Droits de l'Homme et du Citoyen. 